\title{
Heart versus brain: a case of ictal asystole in temporal lobe epilepsy
}

\author{
Ahmed Yassin ${ }^{1}$, Belal Aldabbour ${ }^{1 *} \mathbb{D}$, Anto Bagić ${ }^{2}$ and Alexandra Urban ${ }^{2}$
}

\begin{abstract}
Background: Ictal asystole is a rare phenomenon. Most reported cases are in persons with long-standing focal epilepsy originating from the temporal lobe. Its occurrence may complicate the clinical presentation or delay diagnosis, and it is thought to be associated with increased risk of sudden unexpected death in epilepsy.

Case presentation: We report the case of a 55-year-old female person with epilepsy who suffered ictal asystole for $10 \mathrm{~s}$ while under monitoring at the Epilepsy Monitoring Unit. We then review briefly the pathophysiology and current management modalities for this phenomenon.

Discussion: The first step in management of this condition is usually the optimization of anti-seizure drugs. In our case, a 2-year fall-free period was achieved with optimization of medical treatment. Pacemaker implantation can also be attempted to prevent ictal asystole-related falls and injury, while refractory cases may benefit from epilepsy surgery in terms of both seizure control and prevention of ictal asystole.
\end{abstract}

Keywords: Ictal asystole, Ictal bradycardia, Arrhythmia, Focal epilepsy

\section{Background}

Cardiac arrhythmias frequently accompany seizures. While tachyarrhythmia is the most common manifestation [1], ictal bradyarrhythmia (IB) and ictal asystole (IA) are rare [2]. IA is present in $0.22-0.4 \%$ of seizures [3-5] and is an active area of interest for both neurologists and cardiologists. IAinduced syncope may confuse the clinical picture or delay a diagnosis of epilepsy [6]. There are reports that link the occurrence of IB and IA with an increased risk of sudden unexpected death in epilepsy (SUDEP) $[7,8]$. Finally, IB and IA are a demonstration of a clinically challenging electrical interaction between the brain and heart $[9,10]$. We report a 55year-old person with epilepsy who suffered a 10-s IA while under monitoring at the Epilepsy Monitoring Unit (EMU).

\section{Case presentation}

A 55-year-old female person with epilepsy was referred to the EMU for spell classification and anti-seizure drugs (ASDs) optimization. At age eight, she started to have episodes of staring that were diagnosed as absence seizures. These episodes did not resolve with age, but they

\footnotetext{
* Correspondence: belal90md@gmail.com

${ }^{1}$ Department of Neurosciences, Neurology Division, King Abdullah University Hospital (KAUH), P.O. Box (630001), Irbid 22110, Jordan

Full list of author information is available at the end of the article
}

became often associated with aura in the form of auditory hallucinations with left-sided numbness and tingling. The aura recurred several times monthly, and lasted between minutes to hours sometimes, but it was not always associated with impaired awareness or followed by a staring spell. Her seizures persisted despite multiple ASDs and ongoing polytherapy (levetiracetam $1500 \mathrm{mg}$ twice a day, lamotrigine $150 \mathrm{mg}$ twice a day, lorazepam $0.5 \mathrm{mg}$ three times a day, and phenobarbital $64.8 \mathrm{mg}$ once a day). Her brain MRI was unrevealing of focal lesions.

During her stay at the EMU with withdrawal of ASDs, the patient had a spell of what she described as loud ringing in her head and left side tingling. The EMU technician was talking to her when she collapsed suddenly and fell backwards on the bed. She then developed quick, successive myoclonic jerks of all four limbs, which lasted for 10 seconds. Following the event, the patient was disoriented to place, with a delay in answering questions and obeying commands, returning to her baseline in 10 minutes.

Figures 1, 2 and 3 illustrate EEG recording of the spell with the accompanying ECG demonstrating IA. The patient's resting heart rate prior to the reported event had been stable and ranged between 75 and 95 beats per 


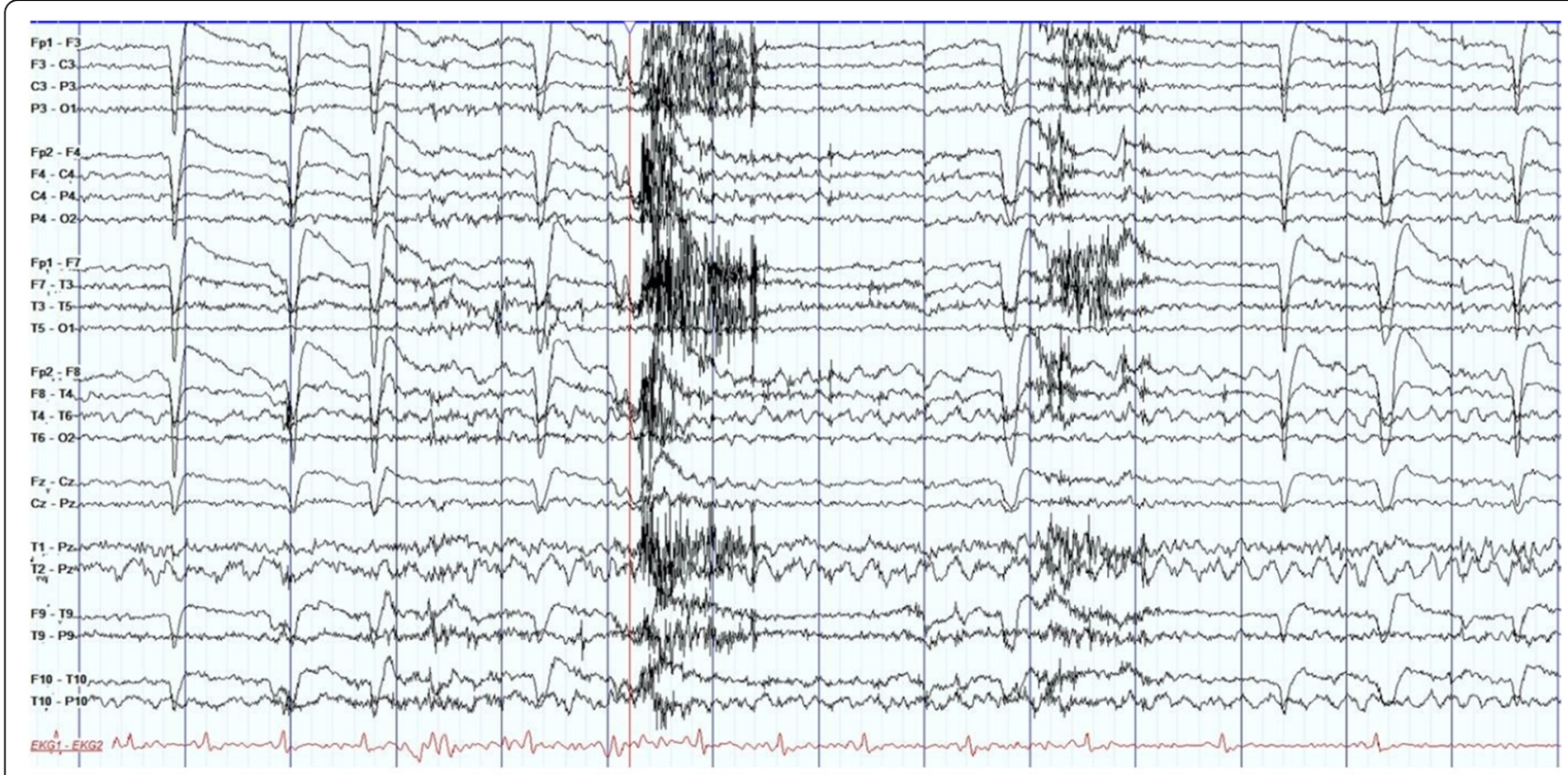

$\mathrm{HFF}=70 \mathrm{~Hz}, \mathrm{LFF}=1 \mathrm{~Hz}$

Fig. 1 Epoch A of the EEG recording demonstrates seizure onset. The electrographic seizure starts with a semi-rhythmic $4.5-\mathrm{Hz}$ activity over the right temporal region. Starting from 9th second, heart rate begins to drop as demonstrated on the ECG strip

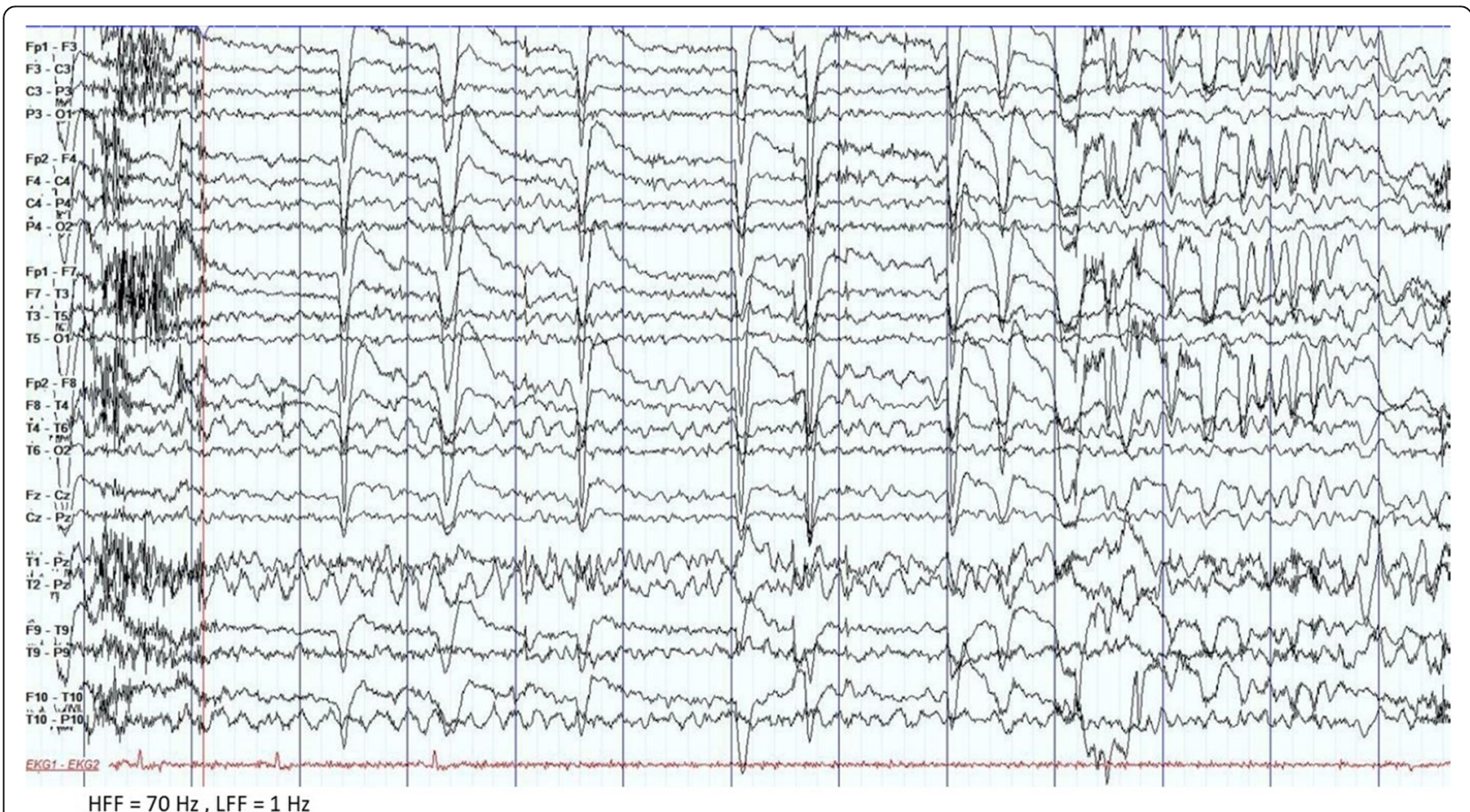

Fig. 2 Epoch B of the EEG recording demonstrates onset of IA. Heart rate drops from 90 beats per minute to 60 beats per minute. Seven seconds later, the patient develops asystole for $10 \mathrm{~s}$ 


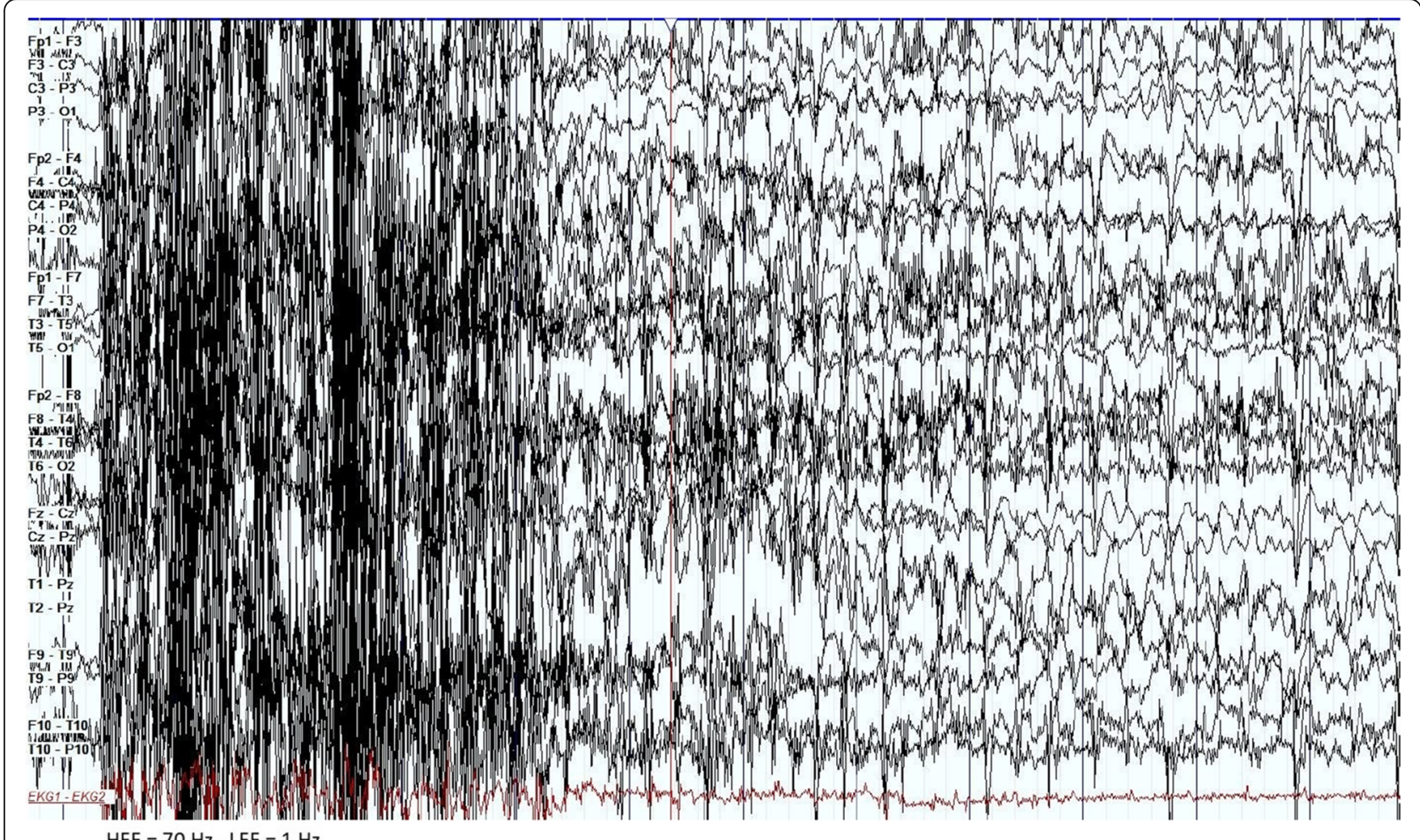

Fig. 3 Epoch C of the EEG recording demonstrates return of spontaneous heart rate. The asystole resulted in cerebral hypoperfusion and syncope. Muscle artifacts are due to myoclonic jerks secondary to cerebral hypoperfusion. ECG strip demonstrates return of spontaneous heart rate

minute. The electrographic seizure starts with a semirhythmic $4.5 \mathrm{~Hz}$ activity over the right temporal region, while heart rate begins to drop starting from the 9th second (Fig. 1). Seven seconds later, the patient develops asystole for $10 \mathrm{~s}$ (Fig. 2). Muscle artifacts (Fig. 3) are due to myoclonic jerks secondary to cerebral hypoperfusion, and the ECG strip demonstrates return of spontaneous heart rate. The recordings were made using the 2016 US-manufactured Xltek EMU40Ex EEG System.

On subsequent visits, lamotrigine was increased to $300 \mathrm{mg}$ twice a day, levetiracetam dose was unchanged, and phenobarbital was tapered off. She still takes lorazepam for anxiety disorder. Two years after the event, the patient is still having focal seizures with or without impaired awareness about once monthly, but no further falls or syncopal events were reported after optimization of ASDs.

\section{Discussion}

In agreement with other previous studies [11, 12], a recent systematic review in 2017 [13] which examined 157 case reports of patients with IA (between 1983 and 2016) identified the left hemisphere (62\% of cases included in the systematic review) and the temporal lobes $(80-82 \%)$ as the most frequent seizure onset zone with associated IA. It also confirmed previous data $[3,12]$ that linked IA to focal-onset $(100 \%$ of cases included in the systematic review), long-standing, and drug-resistant epilepsy (72\%). The average delay between onset of epilepsy and onset of IA in the systematic review was 14 years.

Ictal arrhythmias are thought to result from an imbalance between sympathetic and parasympathetic autonomic cardiovascular discharges [2], with higher parasympathetic outflow leading to IB and IA. This imbalance is hypothesized to be the result of seizureinduced hyperexcitation coupled with chronic changes in neuronal networks secondary to drug-resistant epilepsy $[13,14]$. The central autonomic structures located in the deep temporal lobe, namely the insular cortex and amygdala, are thought to be at the center of these changes [15-17].

Syncope is associated with IA episodes lasting longer than $6 \mathrm{~s}$, and it may recur with future seizures [18]. There is debate in the literature over the optimal management of patients with IA. Generally, a better control of seizures with ASDs should be attempted first [19]. In our case, the patient continues to be fall-free 2 years after optimization of her ASDs. Pacemaker implantation can be reserved for those who fail to become fall-free on ASDs alone [18]. Cases of drug-resistant epilepsy associated with IA might benefit from epilepsy surgery in terms of both seizure control and prevention of IA $[14,18,20,21]$. 


\section{Abbreviations}

ASDs: Anti-seizure drugs; EMU: Epilepsy Monitoring Unit; IA: Ictal asystole; IB: Ictal bradyarrhythmia; SUDEP: Sudden unexpected death in epilepsy

\section{Acknowledgements}

Not applicable

\section{Authors' contributions}

$A Y$ and $A U$ worked with and managed the reported case. $A B$ was consulted on the case as an expert in the field. All authors contributed to literature review and writing the manuscript. BA prepared the final draft and took care of the submission process. All authors read and approved the final manuscript.

\section{Authors' information}

$A B$ is Chief of Epilepsy Division at UPMC and founder of the UPMC Brain Mapping Center. Besides his solid experience and contributions to the field of neurophysiology and electrophysiology, $A B$ is among the most active members in the American Clinical Magnetoencephalography (MEG) community and was one of five founders of the American Clinical MEG Society.

\section{Funding}

None

\section{Availability of data and materials}

Available from $\mathrm{AU}$ upon reasonable request

\section{Ethics approval and consent to participate}

IRB approval is not required by the institution for case reports where sufficient anonymization of patient information is guaranteed.

\section{Consent for publication}

Patient consent for publication was obtained as necessary.

\section{Competing interests}

The authors declare that they have no competing interests.

\section{Author details}

'Department of Neurosciences, Neurology Division, King Abdullah University Hospital (KAUH), P.O. Box (630001), Irbid 22110, Jordan. ${ }^{2}$ Department of Neurology, Epilepsy Division, University of Pittsburgh Medical School and UPMC, Pittsburgh, USA.

Received: 19 November 2019 Accepted: 13 January 2020

Published online: 17 January 2020

\section{References}

1. Keilson MJ, Hauser WA, Magrill JP. Electrocardiographic changes during electrographic seizures. Arch Neurol. 1989;46(11):1169-70.

2. Benditt DG, van Dijk G, Thijs RD. Ictal asystole: life-threatening vagal storm or a benign seizure self-termination mechanism? Circ Arrhythm Electrophysiol. 2015;8(1):11-4

3. Rocamora R, Kurthen M, Lickfett L, Von Oertzen J, Elger CE. Cardiac asystole in epilepsy: clinical and neurophysiologic features. Epilepsia. 2003;44(2):179-85.

4. Schuele SU, Bermeo AC, Alexopoulos AV, Locatelli ER, Burgess RC, Dinner DS, et al. Video-electrographic and clinical features in patients with ictal asystole. Neurology. 2007;69(5):434-41.

5. Strzelczyk A, Cenusa M, Bauer S, Hamer HM, Mothersill IW, Grunwald T, et al. Management and long-term outcome in patients presenting with ictal asystole or bradycardia. Epilepsia. 2011;52(6):1160-7.

6. Rossetti AO, Dworetzky BA, Madsen JR, Golub O, Beckman JA, Bromfield EB. Ictal asystole with convulsive syncope mimicking secondary generalisation: a depth electrode study. J Neurol Neurosurg Psychiatry. 2005;76(6):885-7.

7. Al-Awwad AA, Katyal R, Herren CL. Ictal Asystole in temporal lobe epilepsy: a possible cause of sudden unexplained death - a case report. Neurodiagn J. 2018:58(4):213-7.

8. Langan Y, Nashef L, Sander JW. Sudden unexpected death in epilepsy: a series of witnessed deaths. J Neurol Neurosurg Psychiatry. 2000;68(2):211-3.

9. Sanchez-Borque P, Gonzalez-Giraldez B, Benezet-Mazuecos J, Miracle A, Crosa J, Rubio JM. Ictal asystole: a condition between neurology and cardiology. Int J Cardiol. 2019;278:104-7.
10. van Westrhenen A, Thijs RD. Ictal asystole: how to unveil the hidden ties between the brain and the heart. Int J Cardiol. 2019;278:147-8.

11. Tinuper P, Bisulli F, Cerullo A, Carcangiu R, Marini C, Pierangeli G, et al. Ictal bradycardia in partial epileptic seizures: autonomic investigation in three cases and literature review. Brain. 2001;124(Pt 12):2361-71.

12. van der Lende M, Surges R, Sander JW, Thijs RD. Cardiac arrhythmias during or after epileptic seizures. J Neurol Neurosurg Psychiatry. 2016;87(1):69-74.

13. Tenyi D, Gyimesi C, Kupo P, Horvath R, Bone B, Barsi P, et al. Ictal asystole: a systematic review. Epilepsia. 2017:58(3):356-62.

14. Choudhary N, Deepak KK, Chandra PS, Bhatia S, Sagar R, Jaryal AK, et al. Comparison of autonomic function before and after surgical intervention in patients with temporal lobe epilepsy. J Epilepsy Res. 2017;7(2):89-98.

15. Oppenheimer SM, Wilson JX, Guiraudon C, Cechetto DF. Insular cortex stimulation produces lethal cardiac arrhythmias: a mechanism of sudden death? Brain Res. 1991;550(1):115-21.

16. Catenoix H, Mauguiere F, Guenot M, Isnard J, Ryvlin P. Recording the insula during ictal asystole. Int J Cardiol. 2013;169(2):e28-30.

17. Healy B, Peck J. Bradycardia induced from stimulation of the left versus right central nucleus of the amygdala. Epilepsy Res. 1997;28(2):101-4.

18. Bestawros M, Darbar D, Arain A, Abou-Khalil B, Plummer D, Dupont WD, et al. Ictal asystole and ictal syncope: insights into clinical management. Circ Arrhythm Electrophysiol. 2015:8(1):159-64.

19. Kohno R, Abe H, Akamatsu N, Benditt DG. Long-term follow-up of Ictal Asystole in temporal lobe epilepsy: is permanent pacemaker therapy needed? J Cardiovasc Electrophysiol. 2016;27(8):930-6.

20. Ichikawa N, Fujimoto A, Okanishi T, Sato K, Baba S, Itamura S, et al. Ictal Asystole induced by right posterior quadrant epilepsy: report of a radically treated case. World Neurosurg. 2018;120:337-42.

21. Ballendine S, Shahab I, Perez-Careta M, Taveras-Almonte FJ, Martinez-Juarez IE, Hernandez-Vanegas LE, et al. Resolution of ictal bradycardia and asystole following temporal lobectomy: a case report, and review of available cases using pacemakers. Epilepsy Behav Rep. 2019;12:100333.

\section{Publisher's Note}

Springer Nature remains neutral with regard to jurisdictional claims in published maps and institutional affiliations.

\section{Submit your manuscript to a SpringerOpen ${ }^{\circ}$ journal and benefit from:}

- Convenient online submission

- Rigorous peer review

- Open access: articles freely available online

High visibility within the field

- Retaining the copyright to your article

Submit your next manuscript at $\boldsymbol{\nabla}$ springeropen.com 